\title{
Holistic housing pathways for Australian families through the childbearing years
}

\author{
Melanie Spallek \\ m.spallek@uq.edu.au University of Queensland, Australia \\ Michele Haynes \\ Andrew Jones
}

(Received November 2013 Revised April 2014)

\section{Abstract}

For the previous generation, the typical housing tenure pathway in Australia was more clearly defined, with young adults leaving the family home to marry and experience the birth of the first child while residing in a rental home, before entry into home ownership. For the first time in Australia, longitudinal data is available that allows the examination of housing tenure transitions along with other life events, in particular the birth of children, marital transitions and changes in employment. Sequences of tenure transitions and life events were derived for a large sample of individuals using ten waves of data (2001-2010) from the longitudinal Household Income and Labour Dynamics in Australia (HILDA) survey, with a focus on families with children or of childbearing age. The statistical method of multichannel sequence analysis was used to identify a typology of housing pathways from these data sequences. Half of all individuals in the sample do not experience any transitions in housing tenure status during the period of the survey and these people record notably fewer transitions in marital status. The main typologies identified were related to transitioning into home ownership, with the birth of a child occurring either before or after the transition. Previously, some individuals also entered home ownership before the birth of their first child rather than after, but it was not acknowledged as a major housing pathway as it is now. In this study, the majority of housing tenure and life event sequences showed that individuals were already married by the time of transitioning into home ownership. Pathways are now more diverse with transitions into home ownership often occurring both before and after the birth of a child, with marriage preceding the decision to buy a home.

Keywords: Housing tenure, pathways, sequence analysis, multi-channel, life course, family, children, longitudinal survey data

\section{Introduction}

Existing literature assumes that there is an appropriate order and timing for transitions of key life-events and it has been hypothesised that diverting from this order will lead to negative outcomes later on in life (George, 1993; Harley \& Mortimer, 2000; Hogan \& Astone, 1986). The traditional Australian family life cycle in the 1950s was clearly defined as entering into marriage, the birth of the first child while remaining in a rental home, followed by an entry into home ownership, the birth of more children and then remaining in this same home until old age (Kendig, 1981; Kendig,
1984; Winter \& Stone, 1999). This was challenged by the concept of 'choice', which led to the loosening of traditions and resulted in a diversity of life styles (Clapham, 2005; Giddens, 1991). Many of these changes are associated with changing life course patterns, for example, individuals are now spending more time in further education, which can explain delayed entry into the labour force; union formation that may or may not result in marriage, and timing for the birth of a first child that has been pushed back within a person's life course in the twenty-first century (Beer \& Faulkner, 2009). 
Employment is one factor that characterises a household and influences housing demand, as housing needs to be paid for and for many, employment provides the income (Clapham, 2005). Specifically for dual income families, the decisions on employment, fertility and housing are interconnected.

The trends examined in this paper have taken place against a background of increasing difficulty for young individuals and families to attain home ownership. In Australia the main pathway into first home ownership is via the private rental market. In contrast, social housing is a small, residualised sector, which for many years has played little role in home ownership attainment by young families. Many Australians in their 20s and 30s, after leaving the family home, rent in the private sector while saving for a deposit to attain a mortgage and begin the process of paying off their 'own home'. Between the 1950s and mid-1970s the predominant housing career of young Australians was clear: after living with parents or in the private rental market, they married, had their first child and then entered home ownership (Yates, 2007). This pattern underpinned Australia's high rate of home ownership (approximately 70 percent of all households) since the late-1950s. However, since the mid-1970s, younger households have found it increasingly difficult to make this transition from renting in the private market into home ownership. Yates has documented the steady decline in age specific home ownership rates for younger households from the mid-1970s to the early twentyfirst century. Using Census data, she records that between 1976 and 2001, home ownership rates for those in the 25-29 year old age group declined by 11 percentage points (from 54 per cent to 43 per cent), by 10 percentage points (from 67 per cent to 57 per cent) for those in the 30-34 year old age group, and by 6 percentage points (from 72 per cent to 66 per cent) for those in the 35-39 year old age group (Yates, 2007). This decline has led many observers including Yates (2007) to ask, 'Has the great Australian dream (of home ownership) ended?'

A number of explanations have been suggested for the increasing difficulties faced by young Australians in attaining (and retaining) home ownership (Yates, 2007, 2008). Of particular significance is the increase in the deposit gap to income ratio, which in the 2000s was 3 to 4 times greater than it had been in the 1970s (Yates, 2007). This was exacerbated by a spike in house prices in the early 2000s, which resulted in a doubling of the house price to income ratio from its long run average. Generally, house prices have remained at high levels throughout the study period (20012010); Australia did not experience a marked fall in house prices associated with the Global Financial Crisis (GFC) as happened in several other countries. The capacity of young families to obtain a deposit and meet repayments has also been impacted negatively by long-term trends towards less secure employment, and increases in separation and divorce. These factors resulting in the decline in the proportion of young households who have attained home ownership is the backdrop to the data reported in this paper, which provides detailed evidence concerning the impact of family formation (and dissolution), fertility and related factors on the transition to first home ownership in the 2000s.

Understanding the pathways through housing transitions is of particular importance in Australia, as the Australian Age Pension is set at a lower rate compared to other countries, assuming outright home ownership and hence low housing costs at the time of retirement (Yates \& Bradbury, 2010). This has long term implications for families that do not attain home ownership, making them vulnerable to poverty in retirement. The concept of linking housing transitions to life events was first developed by Rossi (1955), who concluded that housing transitions are a result of adapting housing needs to changes that have occurred throughout the life course. From around the period 1970-1980 this concept received more attention, and the associated body of literature reported a correlation between housing and key life events (Kendig, 1984; Payne \& Payne, 1977). In fact, it was reported that households ascend three separate but related ladders, namely the employment, the life stage (including relationship formation and birth of first and consecutive children) and the housing ladder, referred to as a housing 'career'.

The term 'career', however implies an upwards notion, and Kendig (1982) defined housing careers as uniform, meaning most of the population follow the same career with the common aim of home ownership. But recent literature (Beer \& Faulkner, 2009; Clapham, 2005) on housing pathways in Australia has emphasised the increasing diversity and discontinuity of housing pathways and the 
emphasis has been on changes to housing 'pathways' rather than housing 'careers'. Badcock and Beer (2000) have found that housing careers do not only move upwards. They acknowledged the falling out of home ownership, and furthermore, that not everyone is making the desirable transition to home ownership. Hence, the expression "housing pathways" appears to reflect the current diverse sequence of housing transitions more appropriately.

Sociological research using retrospective life histories (Baizan, Aassve \& Billari, 2004; Beer, Paris, Faulkner \& Clower, 2011; Boyle, Kulu, Cooke, Gayle \& Mulder, 2008; Feijten \& Mulder, 2002; Kulu, 2008; McDonald \& Merlo, 2002; McLeod \& Ellis, 1982) has previously shown how life course transitions such as entering marriage, birth of a child, getting a new job, all influence the likelihood of a change in housing tenure status. Relationship formation and birth of children were identified as the primary triggers for a housing transition. In recent times, these life-events have become less predictable due to underlying changes related to the acceptance of social circumstances: the social expectation to marry has declined, and there are now several other socially acceptable alternatives to traditional marriage, including cohabiting, single life and same sex relationships (Hunt, 2005). In Australia, the birth of the first child is no longer a primary trigger for a housing transition, with one third of Australian women predicted to be childless in the future, while on the other hand divorce is increasingly associated with tenure transitions (Beer \& Faulkner, 2009).

The decision to undertake a tenure transition is also based on opportunities in terms of availability and accessibility of suitable housing and financial resources. Housing requires payment, and therefore it is important that a family has the financial capacity to pay for it, which in turn is strongly linked to income, education, employment status and finance, as well as household type and lifestyle choices (Clapham, 2005; Giddens, 1991).

Most recent Australian research on housing pathways has been conducted taking a qualitative approach or by using primarily quantitative crosssectional data, focussing on transitions between tenure states at a point in time (Beer \& Faulkner, 2009; Beer et al., 2011). However, to fully understand the inter-relationships among housing transitions and life course events, longitudinal data is required (George, 1993). During the twenty-first century there has been an increase in the number of studies analysing the interaction between lifeevents and housing transitions using longitudinal quantitative survey data and most of these have been conducted by international researchers (Clark, Deurloo \& Dieleman, 2003; Clark \& Huang, 2003; Kulu, 2005; Kulu \& Milewski, 2007; Michielin \& Mulder, 2008; Mulder, 2006; Mulder \& Lauster, 2010; Pollock, 2007).

Many authors have previously used event history analysis to analyse time until an event occurs (Feijten, 2002; Ginsburg, Steele, Richter, \& Norris, 2010), such as time until birth of a child or time until a change in tenure status. However, the focus with this type of analysis is on the transition itself, detaching it from past and future events. Sequence analysis on the other hand considers the whole sequence of events, putting the transitions into context. In sociology research, sequence analysis is used to address questions such as "Do people share a common (life) trajectory, and if so, how is it defined?" In reality, people deal with multiple roles simultaneously and one single sequence cannot capture an actual insight into the life course (Elder, 1985, 2003). Hence, more than one sequence should be observed in parallel over the same period of time to explain an individual's life experience (Stovel \& Boland, 2004). To better understand patterns of housing tenure transitions, it is crucial to also examine the inter-relationships with transitions in other key life events such as marital status, presence and age of children and employment status. This acknowledges the principle of linked lives which emphasises that individuals are making active decisions and active choices based on opportunities and so create their own pathway, which is the basic principle of the life course approach (Elder, 1978; Neugarten \& Datan, 1973). Some writers have referred to the approach that analyses multiple inter-related pathways as 'holistic' pathways (Pollock, 2007).

Australian research in this area has been extremely limited. The HILDA panel survey is the only source of longitudinal data on housing transitions in Australia and with more than ten waves of data it is now possible to analyse sequences of life events in a ten year window to identify housing tenure pathways for families of childbearing age with and without children under 
the age of 18 years, as defined in the following Section 2.1.

In this paper, housing tenure pathways were investigated using Australian longitudinal panel data over the time period from 2001-2010 and in the context of life experiences of Australian families of childbearing age. Three research questions are addressed:

1. What are the main housing pathways in relation to tenure status that can be identified?

2. What are the inter-relationships between housing pathways and marital status, employment and birth?

3. When do families enter or exit home ownership in relation to the other life-events?

In Section 2 the selection criteria of the analytic sample are described, followed by the list of variables included in the analysis in this paper. Section 3 informs the analytic strategy and results are presented in Section 4 followed by a concluding discussion in Section 5.

\section{Analytic Sample and Variables}

\subsection{Sample}

For this research, data from ten successive waves of the HILDA longitudinal survey were analysed. HILDA is a nationally representative householdbased panel study that has been collecting data annually since 2001. HILDA provides a rich source of data on economics, well-being, labour market and family dynamics over the life course. A total of 7,682 households were interviewed at wave one, which resulted in 13,696 interviewed individuals aged 15 years and older. More information about the study design can be found online in the first report of the HILDA discussion papers series by Wooden and Watson (2001).

The analytic sample is restricted to families with children or who are of childbearing age, covering the time period from 2001-2010. Families of childbearing age include individuals with own children under the age of 18 years either living in their household or elsewhere, independent of the individuals' marital status at wave one. With this definition, couple families, as well as single parent families, both male and female, are included in the sample. Additionally, individuals without children but of childbearing age were included if they were males aged 44 years or less and females aged 41 years or younger at wave one. These age limits were chosen, as the occurrence of a birth decreases beyond this age. A sequence analysis of data across all ten waves requires a dataset that is balanced, with observations at each wave for all individuals. Hence, only individuals who were interviewed at each wave from 2001 to 2010 were included. The final analytic sample included 4,345 individuals of childbearing age and who had a complete interview pattern; hence all individuals included in the sample were followed through for ten years, regardless of their experiences.

\subsection{Variables}

The main focus of this study is housing pathways, particularly related to tenure change. Housing pathways can be translated into sequences of housing tenure states. Specific life events were also examined in parallel to changes in tenure status, in particular changes occurring between waves in marital status, age of youngest child in the household and changes in employment status. A state or status records basic information about an individual, and in our research this information is four dimensional, covering information on housing tenure status and demographic information. Housing tenure status was categorised into [1] paying off/owning a home $(n=2,453$ at wave 1 , of which $n=443$ had achieved outright home ownership), [2] renting (private sector) $(n=1,024)$, [3] renting (public sector) $(n=142)$, [4] other $(n=81)$ and [5] living with parents $(n=645)$. The housing tenure status 'renting (private sector)' was defined as renting from a private landlord/real estate agent, a caravan park owner/manager, an employer, or from a manager of a complex/village, whereas the housing tenure status 'renting (public sector)' was defined as renting from a government housing authority, or a community/cooperative housing group. Housing tenure status categorised as 'other' included rent free tenure arrangements and renting arrangements where it was not further specified who the household rents from. Marital status was categorised into [1] legally married $(n=2,266$ at Wave 1), [2] de facto $(n=550)$, [3] separated, divorced and widowed $(n=314)$ and [4] never married and not de facto $(n=1214)$. Age of youngest own child was grouped into four categories, with [0] indicating no own children present in the household ( $n=1,935$ at Wave 1), [1] own child aged five and under present in the household $(n=1,305)$, [2] own child in the household aged $6-18$ years $(n=1,099)$, and [3] representing own adult child(aged 18 and above) are present in the household ( $n=6$ at wave 
one, but consistently increases to $n=281$ at wave 10). Regarding employment status, three main groups were considered, [1] employed $(n=3,308)$, [2] unemployed $(n=203)$ and [3] not in the labour force $(n=834)$.

\section{Analysing Sequences}

In this paper, we consider four life event sequences, with transitions in housing tenure of primary interest. Sequences of transitions in marital status, employment status, and age group of youngest own child in the household were considered as potentially motivating events for a transition in housing tenure. Before analysing the transitions as sequences, transition probabilities for housing tenure and life events were explored separately. Transition probabilities represent the overall probability of moving from one state to another or remaining in the same state. In our paper we refer to wave to wave transition probabilities, as these probabilities are not based on individual longitudinal characteristics and are neither linked to a point in time (Gabadinho, Ritschard, Muller \& Studer, 2011). This step of analysis allowed the identification of transitions that were more likely to occur than others. The distributions of sequences were then explored separately by examining the ten most frequent sequences for each of the corresponding transition variables, that is, housing tenure status, marital status, employment status and age group of youngest child. Furthermore, for each of these demographic variables, transversal state frequency plots of tenure status were produced. Details for the ten most frequent sequences as well as the transversal state frequency plots (Figures A.5-A.8) are shown in the Appendix.

\subsection{Defining multi-channel sequences}

Multi-channel sequence analysis (MCSA) (Gauthier, Widmer, Bucher \& Notredame, 2010; Pollock, 2007) using the Optimal Matching algorithm as applied in Pollock (2007), was used to identify patterns of inter-relationships among housing tenure pathways, marital transitions, the birth of a child and changes in participation in the labour market. To represent an individual's combined status across all four variables at each wave, a four digit number was used. The first digit refers to the individual's housing tenure status, the second digit refers to the marital status, the third digit refers to the employment status and the fourth digit represents responsibility for children by age group. For example, the combined status 1211 at one point in time identifies an individual who is paying off/owning the home [1...], is in a de facto relationship [.2..], is employed [..1.], and has an own child younger than 5 years in the household [...1]. Table 1 illustrates combined sequences for four pre-selected individuals in the sample. The first sequence describes the pathway of an individual who lives with his/her parents, has never been married, is employed and has no children at wave 1 in 2001 [5410]. From wave 1 to wave 2 this individual leaves the parental home and transitions to a rental home, enters a de facto relationship, remains employed and still has no children [2210]. Between wave 4 and wave 5 this individual transitions from a de facto relationship to marriage [2110], and transitions into home ownership in the following wave [1110]. A large number of different transitioning patterns can be observed (there are 180 possible combinations to explain a single state using these four digits) and therefore the probability that two individuals follow exactly the same ten year trajectory is small.

Table 1. An illustration of four combined sequences of events over ten years

\begin{tabular}{|l|l|}
\hline & Wave-to-wave sequence \\
\hline Person & $2001-2002-2003-2004-2005-2006-2007-2008-2009-2010$ \\
\hline 1 & $5410-2210-2210-2210-2110-1110-1110-1110-1110-1110$ \\
$2210-2210-2210-2210-2211-2211-2111-2111-1111-1111$ \\
$2220-2210-2210-2210-2211-2211-2111-2111-1111-1111$ \\
\hline 3 & $5410-5410-5410-5410-5410-5410-5410-1210-1210-1110$ \\
\hline 4
\end{tabular}

Digit 1= tenure status, digit 2=marital status, digit 3=employment status, 4=age group of youngest child 


\subsection{Approach to Analysis}

Sequence analysis is based on establishing dissimilarities between sequences. It provides information about which sequences are more similar to one another compared to others, by comparing every possible pair of sequences and calculating the 'cost' of transforming one sequence into another. Several algorithms have been used to calculate these transformation costs; these include Optimal Matching, Hamming, and Dynamic Hamming (Gabadinho et al., 2011). For our multichannel sequence analysis, we employed the commonly used Optimal Matching (OM) algorithm to calculate the cost to transform one sequence into another (Abbott \& Tsay, 2000; Martin \& Wiggins, 2011). OM allows three different operations for the transformation process, insertion and deletions (where a state is inserted or deleted) collectively referred to as indel operations, and substitutions or replacements, where one state is substituted by another. Every operation has a cost assigned. Setting the cost for operations is not straightforward and the decision is generally based on known or observed relationships between the states. By transforming one sequence into another, the overall cost is calculated by summing each of the relevant substitution and indel costs. The smallest overall cost to transform one sequence into another is then referred to as the distance between two sequences.

The substitution costs for this analysis were defined as the inverted transition probabilities. Less likely transitions resulted in higher substitution costs, and more common transitions were assigned lower costs. Indel costs were set to 1.5 , which leads to the algorithm favouring substitutions over insertions (Allison, 2009). When the distances were established in terms of costs, Ward's method for hierarchical clustering was used to group individuals with the most similar sequences together, reducing the data to a group of homogenous clusters (Kaufmann \& Rousseeuw, 2005). The most frequent representative sequence for each cluster, was extracted according to a specified representative criterion to characterise the most common sequence of life experiences of individuals within each cluster. The representative criterion applied was a redundancy threshold of $10 \%$, meaning that one sequence $x$ is redundant to another sequence $y$ in one cluster, if $x$ is within a $10 \%$ neighbourhood radius of sequence $y$. The redundancy threshold of
$10 \%$ refers to $10 \%$ of the maximum possible distance between two sequences within one cluster, as it would be calculated by the OM algorithm. Sequences are then sorted in decreasing density order and the sequence with the highest density was extracted as the representative sequence for each cluster (Gabadinho et al., 2011). The different clusters were further examined by exploring the transversal state frequencies, separately for each variable of interest, housing tenure status, marital status, employment status and age of youngest own child in the household. Transversal state frequency plots show frequency distributions of one variable at every wave and were chosen over the more standard sequence index plots, because they show the overall changes and characteristics in a cluster.

The multi-channel sequence analysis using Optimal Matching algorithm was conducted in R ( $R$ Core Team, 2013) using the package TraMineR (Gabadinho et al., 2011; Studer, Ritschard, Gabadinho \& Mueller, 2011).

\section{Results}

The wave to wave transition probabilities indicate that individuals remained in the same tenure between waves with a high probability. Since the focus of this paper is to learn more about these people but to also investigate those who do change tenure and how this relates to changes in other life events, the sample was further classified and considered as two groups being individuals or stayers with stable tenure across all ten waves, and movers who experienced a transition between tenure types at least once during the ten waves of the survey. The 2,295 individuals in stable tenure types (stayers) are comprised of 1,818 (79.2\%) individuals being home owners, 309 (13.5\%) individuals renting (private), 55 (2.4\%) individuals renting (social), $5(0.2 \%)$ individuals in other tenure and $108(4.7 \%)$ individuals living with their parents for the entire period from 2001-2010. The stayers (mean age 36.9 years) were also characterised by being on average eight years older at wave one than the movers (mean age 28.9 years). The stayers tend to already have children (70.5\%) compared to $38.7 \%$ of movers and are more likely to be married $(66.7 \%)$ compared to $35.9 \%$ of movers.

\subsection{Transition Probabilities}

As our focus was on the individuals who experienced at least one tenure transition 
throughout the observed time period from 20012010, we produced transition probabilities for housing tenure states, marital status, employment status and age group of youngest own child separately for stayers and movers (Table 2). A comparison of the transition probabilities for demographic characteristics indicated differences between stayers and movers. Staying married between consecutive waves was dominant in both groups, however, moving into a de facto relationship was more likely amongst the movers (previously never married: 0.11 , previously separated/married/divorced: 0.09) than amongst the stayers (previously never married: 0.04, previously separated/married/divorced: 0.05 ). Remaining in a de facto relationship was less likely amongst movers (0.77) compared to stayers (0.87), with individuals either transitioning into being married (0.13), or ending the relationship (0.10). The transition probabilities for employment status were relatively equally distributed with a higher probability of individuals transitioning into the labour force amongst movers (0.35) compared to stayers $(0.26)$. The transition probabilities related to age of youngest child in the household were very similar for stayers and movers: not having children in the household for two consecutive waves had the highest probability of 0.94 in both groups. Having older children (aged 6 to 18 years) in the household for two consecutive waves was also high (stayers: 0.95; movers: 0.91) (Table 2).
Despite being defined as movers (having at least one tenure transition throughout all ten waves), the probability of staying in home ownership between two consecutive waves was still predominant with a probability of 0.86 . This is equivalent to concluding that not staying in home ownership, hence 'falling out' of home ownership between two consecutive waves has a probability of 0.14 . Most between wave tenure transitions had an 'upward' notion, such as transitioning from renting (private) to owning with probability 0.18 , from renting (social) to renting (private) with probability 0.17 , from other tenure to renting (private) with probability 0.30 , or to owning with probability 0.23 , and from living with parents to renting (private) with probability 0.17 (Table 2).

The substitution costs (derived from the transition rates) are then used within the Optimal Matching algorithm to calculate the dissimilarity matrix between the multi-channel sequences of housing tenure status, marital status, employment status and age of youngest child in the household This final matrix includes the 'distances' between every possible sequence, which relates to the similarity of the multi-channel sequences. The dissimilarity matrix is then subject to a cluster analysis in order to group similar sequences together and define a typology for housing transitions and life events. For the reasons described above, this analysis was undertaken separately for movers and stayers. 
Table 2. Wave to wave transition probabilities for movers and stayers

\begin{tabular}{|c|c|c|c|c|c|c|c|c|c|c|}
\hline \multirow[b]{2}{*}{ Tenure } & \multicolumn{5}{|c|}{ Individuals with stable tenure } & \multicolumn{5}{|c|}{ Individuals with changing tenure } \\
\hline & OWN & RTP & RTS & OTH & PAR & OWN & RTP & RTS & OTH & PAR \\
\hline OWN & 1 & 0 & 0 & 0 & 0 & 0.86 & 0.10 & 0.00 & 0.03 & 0.01 \\
\hline RTP & 0 & 1 & 0 & 0 & 0 & 0.18 & 0.73 & 0.02 & 0.05 & 0.02 \\
\hline RTS & 0 & 0 & 1 & 0 & 0 & 0.07 & 0.17 & 0.72 & 0.03 & 0.01 \\
\hline ОTH & 0 & 0 & 0 & 1 & 0 & 0.23 & 0.30 & 0.02 & 0.43 & 0.02 \\
\hline PAR & 0 & 0 & 0 & 0 & 1 & 0.08 & 0.17 & 0.01 & 0.02 & 0.72 \\
\hline $\begin{array}{l}\text { Marital } \\
\text { Status }\end{array}$ & MAR & DEF & SDW & NM & & MAR & DEF & SDW & NM & \\
\hline MAR & 0.99 & 0.00 & 0.01 & 0.00 & & 0.96 & 0.00 & 0.04 & 0.00 & \\
\hline DEF & 0.08 & 0.87 & 0.01 & 0.03 & & 0.13 & 0.77 & 0.02 & 0.08 & \\
\hline SDW & 0.02 & 0.05 & 0.93 & 0.00 & & 0.04 & 0.09 & 0.87 & 0.00 & \\
\hline NM & 0.01 & 0.04 & 0.00 & 0.95 & & 0.02 & 0.11 & 0.00 & 0.87 & \\
\hline $\begin{array}{l}\text { Employment } \\
\text { Status }\end{array}$ & EMP & UNE & NIL & & & EMP & UNE & NIL & & \\
\hline EMP & 0.96 & 0.01 & 0.03 & & & 0.93 & 0.02 & 0.05 & & \\
\hline UNE & 0.50 & 0.26 & 0.24 & & & 0.52 & 0.27 & 0.21 & & \\
\hline NIL & 0.22 & 0.04 & 0.75 & & & 0.27 & 0.08 & 0.65 & & \\
\hline $\begin{array}{l}\text { Age of } \\
\text { youngest } \\
\text { child }\end{array}$ & None & $0-5$ & $6-18$ & $>18$ & & None & $0-5$ & $6-18$ & $>18$ & \\
\hline No children & 0.94 & 0.04 & 0.01 & 0.01 & & 0.94 & 0.05 & 0.01 & 0.00 & \\
\hline $0-5$ & 0.01 & 0.84 & 0.15 & 0.00 & & 0.02 & 0.89 & 0.09 & 0.00 & \\
\hline $6-18$ & 0.02 & 0.01 & 0.95 & 0.03 & & 0.04 & 0.02 & 0.91 & 0.03 & \\
\hline$>18$ & 0.20 & 0.00 & 0.00 & 0.79 & & 0.26 & 0.00 & 0.00 & 0.74 & \\
\hline
\end{tabular}

$O W N=$ owning; $R T P=$ rent(private); $R T S=$ rent(social); $O T H=o$ ther tenure; $P A R=$ living with parents. $M A R=$ married; $D E F=$ de facto; $S D W=$ separated/divorced/widowed; $N M=$ never married and not de facto $E M P=$ employed; $U N E=$ unemployed; $N I L=$ not in the labour force

0-5=youngest child aged 0-5 years; 6-18=youngest child aged 6-18 years; > youngest child aged $>18$ years.

\subsection{Multi-channel sequence analysis - Results Stayers}

The results from the multi-channel sequence analysis followed by the cluster analysis for grouping similar multi-channel sequences (Table 3), identified two distinct clusters for the stayers $(52.8 \%, n=2,295)$, that are each represented by the following two multi-channel sequences: 1111-1111-
1111-1112-1112-1112-1112-1112-1112-1112 (79.4\%, $\mathrm{n}=1,823)$ and 5430-5430-5410-5410-54105410-5410-5410-5410-5410 (20.6\%, n=472). For the remainder of the paper, sequences will be represented in this State Permanence Sequence (SPS) format for easier recognition of transitions; if a state does not change over a few waves, it will be stated only once followed by a number in brackets, 
which identifies the number of waves the individual has been in this state. Hence, the two representative sequences can be displayed as 1111(3)-1112(7) and 5430(2)-5410(8). The transitions are now apparent, the first sequence cluster represents individuals who own their home, are married, are employed and have children under the age of 5 , transitioning to having children from ages 5 to 18 years as the children continue to grow older. The second sequence cluster identifies individuals living with their parents, not married and not in a de facto relationship, not in the labour force and with no own children in the household. The transition occurring here is in the labour force status, changing from not being in the labour force, perhaps because of full-time study, to being employed.

\subsection{Multi-channel sequence analysis - Results Movers}

The results from the multi-channel sequence analysis and subsequent clustering procedure for the movers $(47.2 \%, n=2050)$ are shown in Table 3. Five distinctive clusters were selected to gain indepth information on housing transitions and interrelated life events (Figures 1-4). The first representative sequence for cluster one was 2112(1)-1112(9) identifying married individuals, employed, with children aged 5-18 transitioning from renting (private) into home ownership (29.3\%, $\mathrm{n}=601$ ). This cluster was described as late home owners, post school-aged children. Compared to the other clusters of 'movers', these individuals were oldest at wave one (mean: 34.7 years, SD 6.7). The representative sequence for the second cluster (13.8\%, $n=282$ ) was 2410(9)-1410(1), embodying individuals that have never been married and are not currently in a de facto relationship, are employed and have no children, transitioning from renting (private) into home ownership. The mean age in this cluster was 29.1 (SD 9.2). This cluster was described as single renters to owners, no children. The third cluster, referred to as home owners, prechildren was represented by the sequence $2110(1)$ $1110(2)-1111(7) \quad(27.0 \%, n=554)$. This group is characterized by married individuals, employed with no children, transitioning into home ownership, followed by having children under the age of 5 a few years later. The average age in this cluster is 27.6 years (SD 7.4). Cluster four represents individuals who have never been married and are not currently in a de facto relationship, are employed and do not have children, moving out from their parents' home into a private rental. The representative sequence for this cluster is $5410(8)-2410$ (2) $(17.1 \%, n=350)$. This cluster embodies the youngest individuals (mean 19.0 years, SD 5.2) and is described as parental home leavers to renters, no children. The fifth cluster, 2110(2)-2111(5)-1111(2) (12.8\%, $n=263)$, characterizes individuals that start off as renting a private property, being married, employed and do not have children. These individuals first have children and then transition into home ownership later on and are hence referred to as traditional home owners, post-pre-school children. The mean age in this cluster is 31.7 years (SD 8.6).

These results show that multiple pathways are followed along the way to home ownership. The fifth cluster being the smallest $(17.1 \%)$, represents the traditional pathway of being married and having the first child in a rental property before entering home ownership when children are still of preschool age. Cluster one is similar, however the individuals do not enter home ownership until the youngest child is of school age. The two pathways identified, different to the traditional pathway, are characterised by individuals who have children after they enter home ownership, and individuals who enter home ownership as a single person. 
Table 3. Representative sequences for each cluster, separated for stayers and movers

\begin{tabular}{|c|c|}
\hline Stayers $(52.8 \%, \mathrm{n}=2295)$ & Movers $(47.2 \%, n=2050)$ \\
\hline \multicolumn{2}{|c|}{ Representative sequences for each cluster } \\
\hline 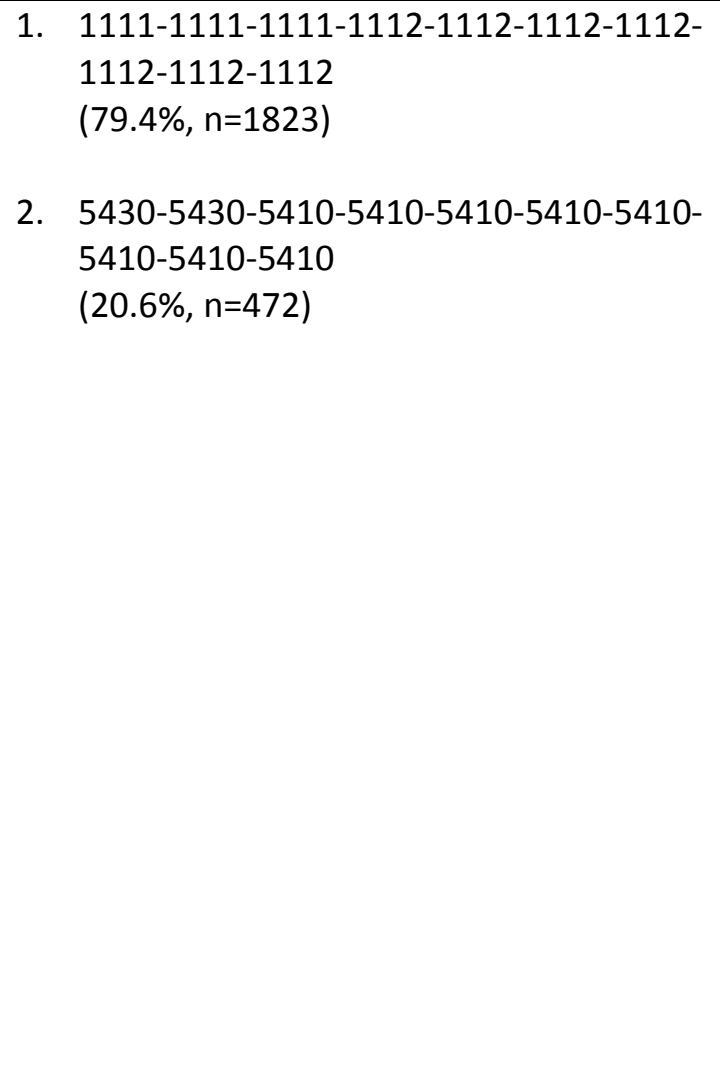 & 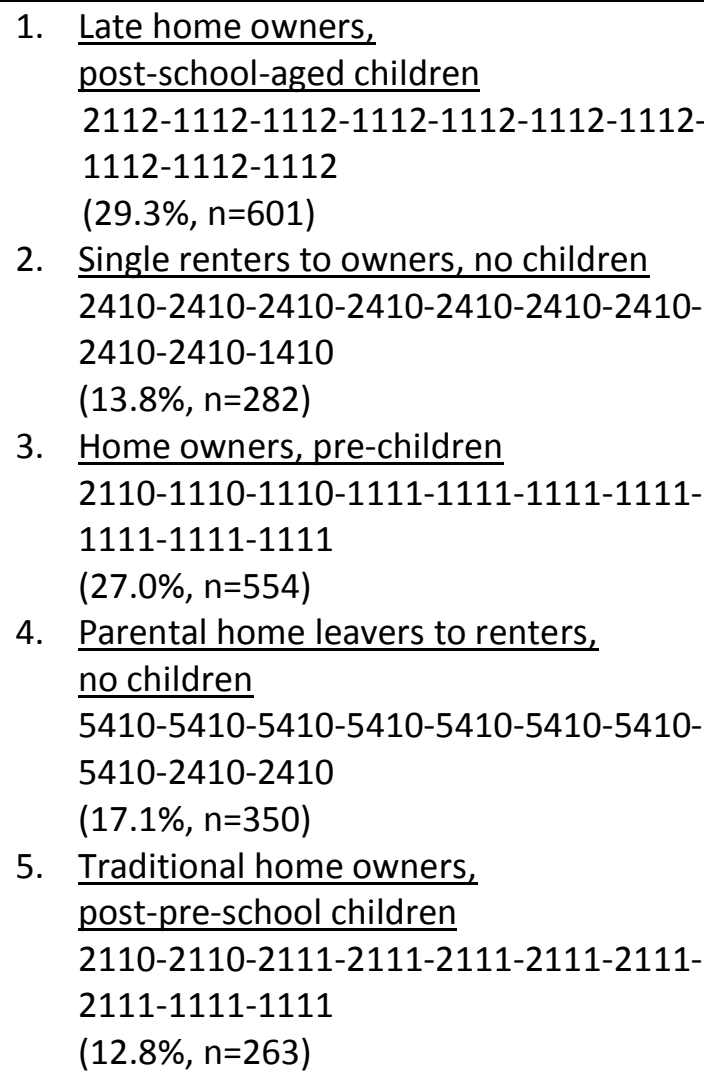 \\
\hline
\end{tabular}

4.4 Transversal state frequency distributions of housing tenure states, marital status, employment status and age of youngest child in the household by cluster of movers

Transversal state frequency plots for every demographic variable within each cluster of movers were produced, to visualize the trends of states across ten waves and to understand the characteristics of each cluster.

For brevity we refer to clusters by the number as defined in Table 3. Figure 1 shows that cluster three and cluster four were associated with the greatest change in the distribution of housing tenure states over ten waves. In cluster three, at wave one, there were $25.1 \% \quad(n=139)$ home owners and $46.8 \%$ $(n=259)$ renters (private); these percentages reverse over time with $85.9 \%(n=476)$ home owners and $8.7 \%(n=48)$ renters by wave ten. This group represents individuals who transitioned into home ownership. Cluster four has the greatest proportion of individuals living with their parents at wave one
(93.1\%; $n=326)$. This number steeply decreased to $10.0 \%(n=35)$ by wave ten, with $30.1 \% \quad(n=105)$ home owners and $48.7 \%(n=170)$ renters (private). Obviously, this cluster represents individuals moving out of the parents' home. The remaining clusters do not show a great change in housing tenure distributions over time, however they differ in their characteristics. Cluster one had consistently high rates of home owners, slightly increasing over time (wave one: $60.1 \%, n=361$; wave ten: $72.1 \%$, $\mathrm{n}=433$ ). Clusters two and five show similar patterns, with a large and relatively stable proportion of renters (private) (cluster two, wave one: $47.9 \%$, $\mathrm{n}=135$; cluster five, wave one: $43.0 \%, \mathrm{n}=113$ ). Note that both clusters show an increase in renters (private), peaking around the middle of the survey, and again decreasing towards the end of the survey. Complementing this pattern for the same clusters, the proportion of home owners decreases in the first half of the survey, increasing again in the second half of the survey. This indicates that within the first half of the survey, individuals were leaving 
home ownership. Cluster five has consistently the highest rates of both renters (social) (wave one: $16.7 \%, n=44$ ) and other tenure (wave one: $10.7 \%$, $\mathrm{n}=28$ ).

Further, the clusters were examined by the transversal state frequencies of marital status, shown in Figure 2. In clusters two, three and four, changes in the distribution of marital status can be observed. Cluster two, which also consistently shows the greatest proportion of renters (private) at each time point, shows a decrease in the proportion of individuals who have never been married and were not in a de facto relationship, from $60.3 \%(n=170)$ at wave one to $33.7 \%(n=95)$ at wave ten. At the same time, the proportion of married individuals increased (wave one: 12.8\%, $n=36$; wave ten: $26.2 \%, n=74)$, whereas the proportion of individuals in a de facto relationship or being separated, divorced or widowed remained stable (de facto, wave one: $11.4 \%, n=32$; separated/divorced/widowed, wave one: $15.6 \%$, $\mathrm{n}=44$ ). Cluster three, which showed a steady increase in the proportion of home owners, also shows a steady increase in married individuals (wave one: $17.2 \%, n=95$; wave ten: $63.5 \%, n=361$ ). In cluster four, which is associated with individuals leaving their parental house, most individuals have never been married at wave one $(98.6 \%, n=345)$. By wave ten, $44.6 \%(n=156)$ are in a relationship (14.6\%, $n=51$ married; $30.0 \%, n=105$ de facto). Cluster one and five show stable proportions of marital states across time, however cluster one has a higher proportion of individuals being married (wave one: $76.9 \%, n=462$ ), compared to cluster five (wave one: $54.0 \%, \mathrm{n}=142$ ).

Employment status distributions were also examined by clusters and showed a stable distribution of individuals being employed (around 75-90\%), unemployed (around 4-10\%) and not in the labour force (around 6-20\%) for clusters one two and three, across all waves (Figure 3 ). Cluster four, relating to individuals leaving the parental house, and forming relationships, additionally show an increase of individuals being employed (wave one: $56.3 \%, \mathrm{n}=197$; wave ten: $86.6 \%, \mathrm{n}=303$ ). Cluster five, wich shows a consistently highest proportion of individuals in other tenure or rental (social), also consistently demonstrates the highest rate of individuals not being in the labour force (wave one: $36.9 \%, n=97$; wave ten: $33.8 \%, n=89$ ).

Next, the distributions of age of youngest child in the household were observed at each time point separately for each cluster (Figure 4). Cluster one, which is characterized by high proportions of home owners and married individuals, shows also a high proportion of individuals with children aged five and below $(55.9 \%, n=336)$ and individuals with children aged $6-18$ years $(30.5 \%, n=183)$. This proportion was reversed by wave ten (individuals with children aged five and below: $19.3 \%, n=116$; individuals with children aged 6-18 years: $54.6 \%$, $\mathrm{n}=328$ ). The main increase in individuals with children aged 6-18 years occurs in the first three quarters of the survey and is parallel to the increase in home owners. Cluster three, which reflects individuals entering home ownership and getting married, shows a decrease in the proportion of individuals not having any children (wave one: $94.0 \%, n=350$; wave ten: $47.1 \%, n=261$ ); and a steep increase in the proportion of individuals with children aged 5 years and under (wave one: $2.9 \%$, $\mathrm{n}=16$; wave ten: $49.3 \%, \mathrm{n}=273$ ). Interestingly, the steep increase in the proportion of home owners (Figure 1) occurs relatively early on and towards the middle of the ten waves, whereas the steep increase of individuals having children aged five years and under, occurred from the middle of the survey towards the end. Clusters two and four consisently show high proportions of individiuals with no children (cluster two, wave one: $78.7 \%$, $\mathrm{n}=222$; cluster four, wave one: $100.0 \%, \mathrm{n}=0$ ). In cluster four, the proportion of individuals with no children slightly decreases to $89.1 \%(n=312)$ by wave ten. Cluster five shows a relatively stable proportion of individuals with children aged 5 years and under (wave one: $46.0 \%, n=121$; wave ten: $39.9 \%, n=569$ ) indicating the birth of children over the ten years. 
Figure 1. Transversal state frequencies of tenure type by clusters one to five for movers
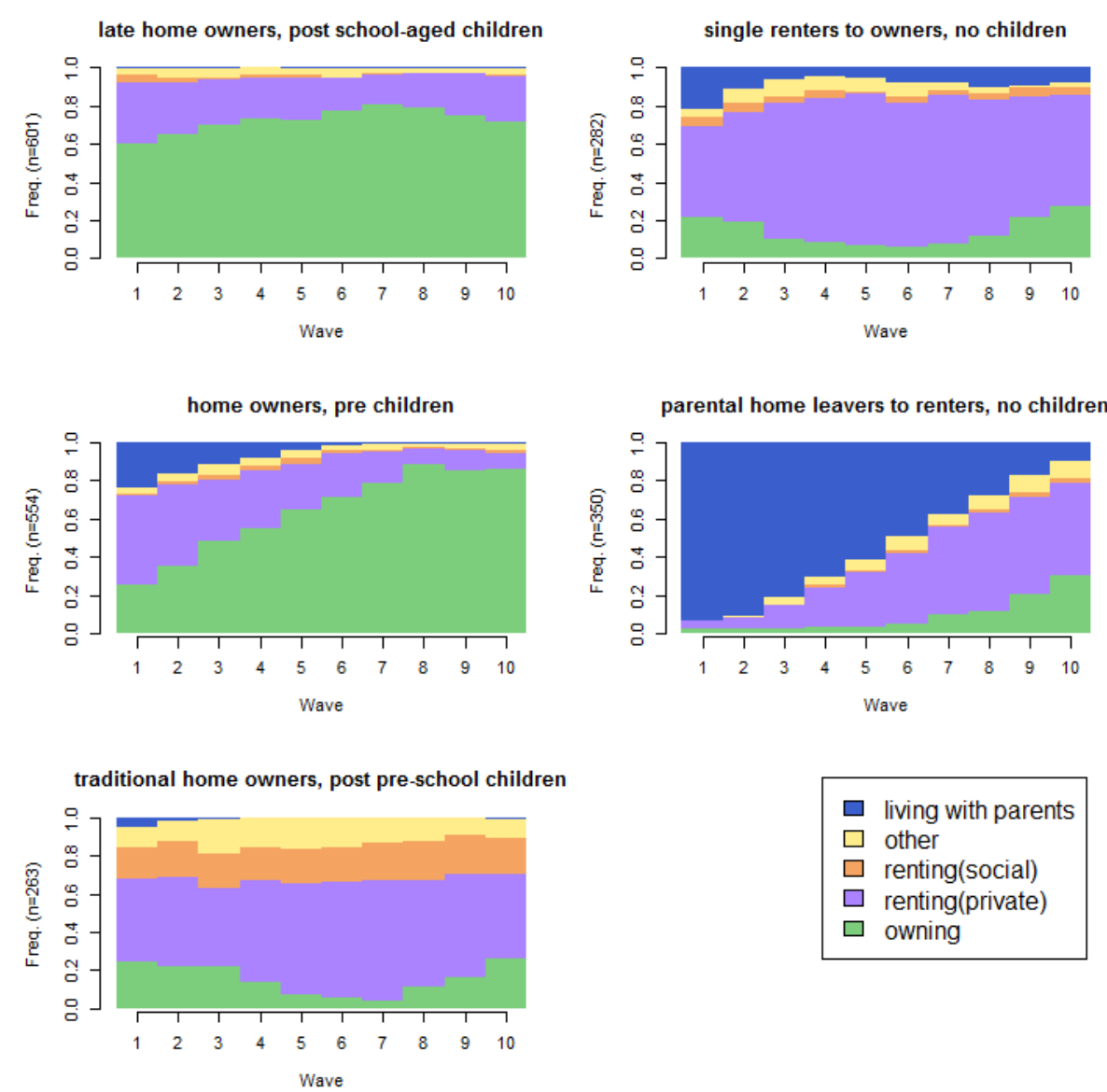

Figure 2. Transversal state frequencies for marital status by clusters one to five for movers
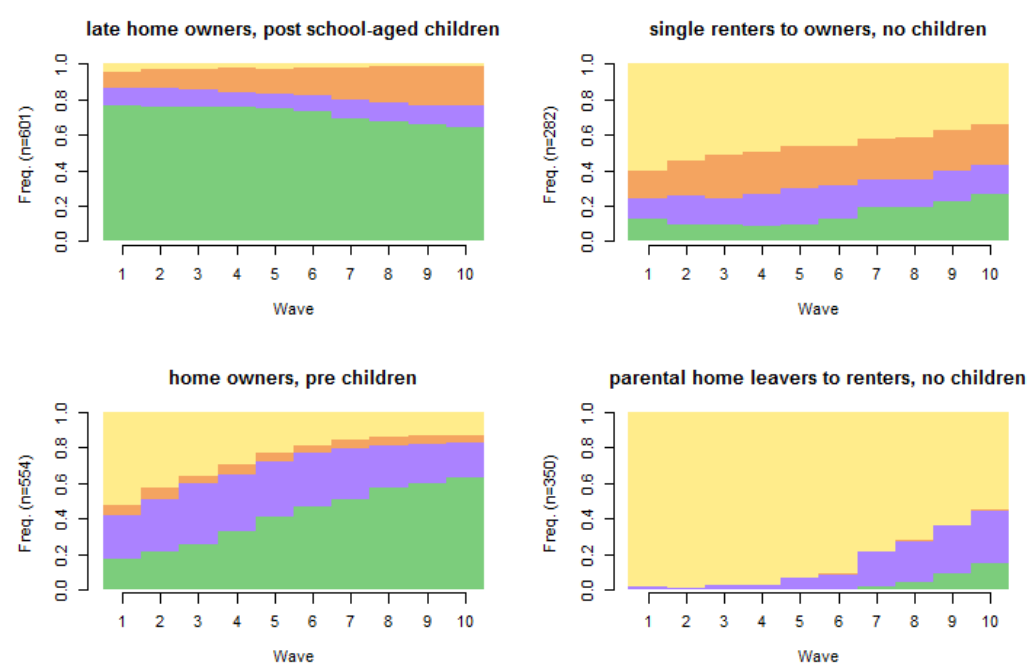

traditional home owners, post pre-school children
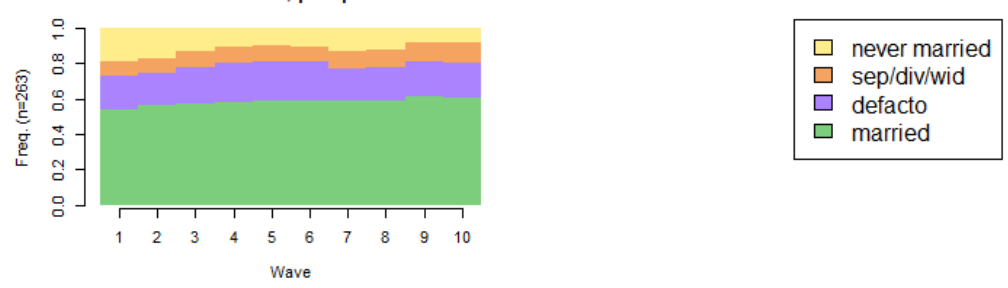
Figure 3. Transversal state frequencies for employment status by clusters one to five for movers
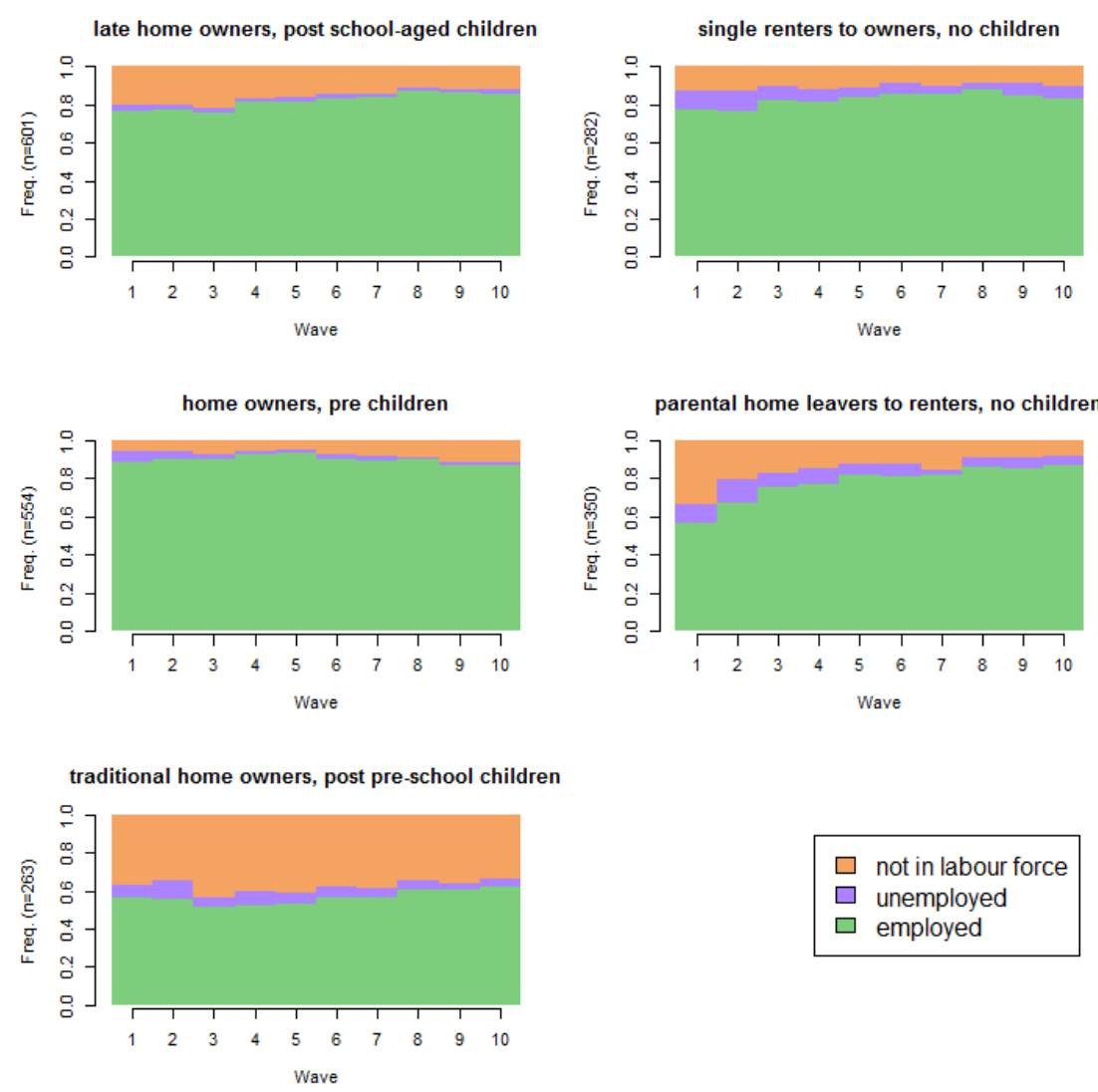

Figure 4. Transversals state frequencies for age group of youngest child by clusters one to five for movers
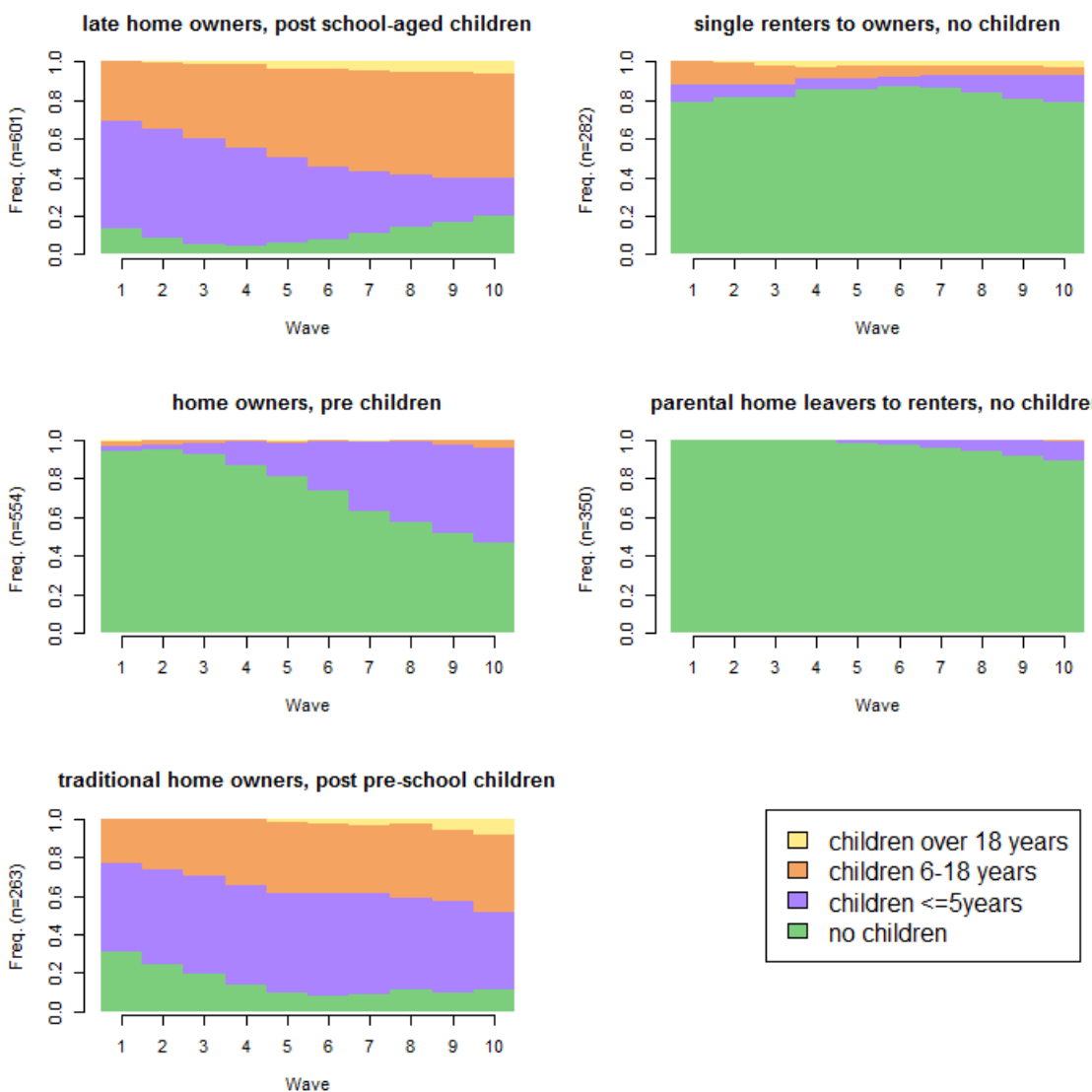

$$
\begin{aligned}
& \square \text { children over } 18 \text { years } \\
& \square \text { children } 6 \text { - } 18 \text { years } \\
& \square \text { children <=5years } \\
& \square \text { no children }
\end{aligned}
$$




\section{Conclusions}

This research set out to answer questions regarding the main housing pathways of adult Australians and the inter-relationships with other life events. The traditional interaction of life events and housing transitions as they were experienced in previous decades, getting married, having a child and then entering home ownership while children were still of pre-school age, have been challenged by life style changes and increasing opportunities to make choices and hence determine one's pathway, as supported by the 'choice' theory, which resulted in different life experiences and pathways. The empirical analysis aimed to identify any evidence for this differentiation by developing a typology of housing pathways and life events for Australian families of childbearing age, with and without children.

For housing tenure pathways in isolation, the analysis revealed that over half of the individuals in the sample $(52.8 \%)$ did not change housing tenure over ten years of the survey and $41.8 \%$ of all sequences were represented by stable home ownership. Although the majority of individuals who did not change housing tenure over time already have transitioned into home ownership $(79.2 \%)$, it is important not to ignore those remaining individuals, around one fifth, who do not enter home ownership during a ten year period. The most frequent sequences including a tenure change showed transitions into home ownership, hence an 'upwards' transition from other tenure categories. However, even within the group of individuals experiencing a housing tenure change, it needs to be acknowledged that there will be individuals who do not enter home ownership, for example switching between renting (private) and renting (social). These pathways were not discussed in this paper as the analysis did not identify them as major pathways in the typology.

Although previous Australian research (Beer \& Faulkner, 2009) indicates that the number of people experiencing a first birth before entering home ownership is decreasing, no other studies support this finding with empirical evidence using longitudinal data. With the availability of ten waves of the HILDA survey, it was possible to examine a window of ten years of housing tenure transitions and life experiences for individuals, acknowledging that a complete housing transition sequence over the life course is three or four times longer than current data allows for. The technique of multichannel sequence analysis has been utilised to produce a typology of typical pathways of housing transitions, intertwined with other significant lifeevents identifying five distinct types of pathways.

The representative pathways for each of the five clusters can be summarised as follows (where total $n$ is the number of individuals in the sample who experienced a housing tenure transition):

Late home owners, post school-aged children (cluster one, $29.3 \%, n=601$ ): oldest individuals at wave one (on average mid-thirties), transitioning into home ownership with children aged 6 to 18 years. Most individuals in this cluster were employed and already married. The representative sequence indicates that these individuals transitioned into home ownership when married with school-aged children.

Single renters to owners, no children (cluster two, $13.8 \%, n=282$ ): aged on average in the late twenties at wave one, mainly renters (private), some transitioning into home ownership, they were starting relationships. The proportion of individuals who were separated, divorced or de facto in this cluster remained relatively constant over the ten waves. The majority was employed and had no children. The representative sequence explains this cluster as individuals who have never been married, with no children, transitioning into home ownership (out of renting (private)).

Home owners, pre children (cluster three, 27.0\%, $\mathrm{n}=554$ ): aged on average in the late twenties at wave one, this cluster incorporates the main transitions into home ownership in the first five years of the survey, as well as the greatest increase in the proportion of individuals getting married overall. These individuals were mainly employed and the cluster demonstrated an increase in the proportion of individuals with children aged five years and under in the second five years of the survey. The representative sequence characterises this cluster as individuals first transitioning into home ownership, and then experiencing the birth of a child. The individuals were already married by the time of the tenure transition.

Parental home leavers to renters, no children (cluster four, $17.1 \%, \mathrm{n}=350$ ): youngest individuals aged late teens to early twenties in wave one, leaving the parents' house and starting relationships in the last five years of the survey. These individuals were also beginning to transition 
into the labour force. Most individuals had no children. The representative sequence summarises this cluster as individuals leaving their parents, moving into a private rental property.

Traditional home owners, post pre-school children (cluster five, $12.8 \%, \mathrm{n}=263$ ): aged around thirty years, contains a large proportion of renters (private), but also the largest (compared to other clusters) group of individuals in renting (public) and other tenure.

The proportion of individuals in home ownership is increasing in the last three years of the survey. Around half of the individuals were married, with little change in the distribution of marital status over time. One third of individuals were not in the labour force at any point in time. The main increase in the proportion of individuals with children aged five years and under occurred during the first five years of the survey. Based on the representative sequence for this cluster, the main characteristics of these individuals are being married and employed, and they first had a child and then entered home ownership, which is the traditional pathway.

The main findings demonstrate that for all individuals who experienced a change in tenure in the sample, one group of individuals entered home ownership first, before the arrival of children in the family, while a smaller group of individuals entered home ownership when children were of pre-school age, this being the previous typical traditional pathway. In both scenarios, marriage precedes transition to home ownership and birth of a first child. Note that previously, some individuals would also enter home ownership before their first child was born, but it was not acknowledged as a major housing pathway as it is now. Similarly, findings presented in this paper did not include pathways characterised by adverse housing tenure transitions associated with marital dissolution or unemployment. Although these pathways were indeed present, they were not frequent enough to be defined as a typical pathway in our five clusters, but they did emerge with increasing separation of the clusters. Previous research suggests a disconnectedness of entry into home ownership and fertility events (Badcock \& Beer, 2000; Winter $\&$ Stone, 1999), however this analysis suggests that the inter-relation of housing pathways, in particular entry into home ownership and marriage and birth, is still present, but the previously ordered sequences of these events have become less clear.
It is important to be aware that there is also a significant group of individuals who enter home ownership on their own, without being in a relationship, which is a pathway that was not likely to be followed in previous decades.

This research has methodological strengths in the use of sequence analysis and longitudinal survey data over ten years; however, there are several limitations. First, the research focus is on major life transitions that occurred primarily in early adulthood, and therefore it was necessary to identify and extract a sub-sample of individuals for whom these transitions were observed. Clearly, the selection of the sample has a strong impact on the major pathways emerging from the analysis. The sample was further restricted to individuals with a complete interview pattern. Given that individuals in unstable housing tenure types are more likely to show incomplete interview patterns, housing pathways that do not include home ownership may be under-represented. There is indeed scope to explore a greater range of pathways, by selecting more clusters to identify other important but less frequently occurring pathways. Second, the availability of ten waves of the HILDA survey data made it possible to analyse a window of housing pathways in Australia; however, identifying an individual's housing tenure in the HILDA survey is not straightforward, as this measure was captured on a household rather than an individual level. A set of rules and assumptions were developed based on relationship statuses within the household. Finally, the timing of some of the transitions is linked to the survey waves, rather than to a date. This leads to assumptions that marriage and entering home ownership, for example, occurred at the same time, although there could have been a gap of up to twelve months between the transitions. The impact of this on the current findings is unclear, but we acknowledge that the exact timing of events is important when the order of events is of interest.

The housing pathways in Australia are undergoing change, and particularly entry into home ownership is of great concern considering the risk of poverty in retirement for families and individuals who did not enter home ownership. More in-depth research is needed to further understand the relationships among the trigger life events, in particular union formation and dissolution, and birth of the first and any successive child, and whether these life events occur within 
five years of the transition to home ownership. This will be particularly important for future analysis of home ownership transitions that also examines relationships with health and well-being, as well as income and wealth related outcomes based on previous life experiences. Data over a longer period of time are required to investigate timing of life events within five years of transitions into home ownership. It is promising that the HILDA survey has been extended to continue data collection over sixteen waves allowing extensions to this research.

Multi-channel sequence analysis is an exploratory technique, which provided information on the order of several processes occurring in early and mid-aged adulthood that are defining major pathways in housing tenure. Future research will use this information to model these processes simultaneously in a multilevel multi-process framework.

\section{Acknowledgements}

This paper uses unit record data from the Household, Income and Labour Dynamics in Australia (HILDA) Survey. The HILDA Project was initiated and is funded by the Australian Government Department of Social Services (DSS) and is managed by the Melbourne Institute of Applied Economic and Social Research (Melbourne Institute). The findings and views reported in this paper, however, are those of the authors and should not be attributed to either DSS or the Melbourne Institute.

\section{Appendix}

Examining the 'top-ten' sequences for housing tenure status, marital status, employment status and age of youngest own child in the household for the entire sample of families with children or of childbearing age.

For each of the four variables of interest, the sequences were firstly examined separately, starting with the sequences for housing tenure status. For housing pathways over ten waves of data with five possible tenure states, and given that all tenure transitions are possible between waves, there are $5^{10}=$ $9,765,625$ possible unique sequences, with the five housing tenure states being: owning, renting (private), renting (social), other, and living with parents. Examining the sequences of housing tenure sequences for the 4,345 individuals in the analytic sample across ten waves of HILDA data, showed that there are 876 unique sequences, with the most frequent sequence being 'owning the home' for all ten waves. The stable home ownership sequence explained $41.8 \%(n=1,818)$ of all housing tenure experiences. Other sequences for which housing tenure did not change include renting their homes from a private landlord $(7.2 \%, n=309)$, living with parents $(2.5 \%, \mathrm{n}=108)$ and social tenure $(1.3 \%, n=55)$. More than half of the individuals $(52.8 \%)$ did not change their tenure status over the period of ten waves. The remaining 'top ten' sequences start with one, two, three, four, six or eight waves of renting their home in the private sector and then transition into home ownership for the remaining waves $(6.3 \%$, $\mathrm{n}=270$ ). Furthermore, 'owning' as the tenure state was the most frequent state at each time point, consistently increasing from $56 \%$ at wave one to $69 \%$ at wave ten. This trend can be explained by higher rates of home ownership with older age (Yates, 2007). A higher percentage of home owners in the sample at the end of the survey in 2010, compared to the beginning of the survey in 2001, suggests that individuals were transitioning into home ownership sometime throughout these ten years.

Focussing now on sequences of marital status across ten waves, there were 492 unique sequences explaining marital status transitions. The four most frequent sequences correspond to a consistent marital status throughout the ten waves, with $43.7 \%(n=1897)$ being married, $11.5 \%(n=499)$ have never been married and are not in a de facto relationship, 3.9\% ( $n=171)$ being separated, divorced or widowed and $3.4 \%$ $(n=148)$ are in a de facto relationship for all ten waves. The remaining six most frequent sequences start with being in a de facto relationship for one, two or four waves and then entering marriage $(3.2 \%, n=134)$, being single for eight or nine waves and then transitioning into a de facto relationship $(1.75 \%, n=76)$, and getting divorced between waves nine and ten $(0.8 \%, n=36)$. The ten most frequent sequences for marital status explain $68.2 \%$ of all possible sequences for marital status.

Summaries for employment status showed 712 unique sequences. Being employed consistently was the predominant sequence $(54.5 \%, n=2366)$. This was followed by not being in the labour force for ten waves $(3.6 \%, n=155)$. The remaining eight most frequent 
sequences can be explained as follows: $3.1 \%(n=134)$ of individuals were not in the labour force for one or two waves and then transitioned to being employed, 1.1\% $(n=47)$ were employed for nine waves, transitioning out of the labour force, $2.8 \%(n=121)$ were employed in the first wave followed by 1-3 waves of not being in the labour force and then taking up employment again. Finally, $1.0 \%(n=45)$ were unemployed in the first wave and employed in the last nine waves and $0.7 \%(n=31)$ were employed in the first wave, unemployed in the second wave and employed for the last eight waves. The sequences for employment status show more variability amongst the ten most frequent sequences compared to the sequences of other statuses. The ten most frequent sequences for employment status explain $66.8 \%$ of all possible sequences.

The sequences relating to age of youngest child in the household demonstrate the least number of unique sequences (312). Of all individuals in the sample $26.8 \%$ $(n=1166)$ did not have children, $10.4 \%(n=451)$ had a youngest child aged $6-18$ years and $3.2 \%(n=138)$ had a youngest child under the age of five throughout all ten waves. The remaining seven sequences within the 'top ten' account for $20 \%(n=866)$ and are characterised by individuals who had children who were growing up, hence these sequences start with individuals who had children under the age of 5 for varying numbers of waves, transitioning to having children aged $6-18$ years old. The ten most frequent sequences explain $57.2 \%$ of the sequences related to age of youngest child in the household.

\section{Transversal tenure state distribution plots}

A useful way of examining sequences is by visualising the distribution of the state, in this case housing tenure status, at each wave. These plots are referred to as transversal state distribution plots (Gabadinho et al., 2011). Housing tenure status distributions are plotted by age group of the individual at wave one, marital status, employment status and the age of youngest child in the household. The transversal housing tenure states by age group in Figure $A 5$ showed that the group corresponding to the largest percentage of individuals living with parents at wave one $(59.9 \%)$ was in the age category of 25 years or less at wave 1 . This percentage consistently decreased across the time span of ten waves to $12.9 \%$ at wave 10 . As expected, this is also the group with the lowest proportion of home owners compared to all other age groups (wave 1: 10.6\%; wave 10: $41.1 \%$ ). The group aged $30-35$ years at wave 1 continued to move into home ownership (wave 1: 42.5\%; wave 10: 65.6\%) and move out of the parental home (wave 1: 9.8\%; wave 10: $2.5 \%)$ over the ten year period. Individuals renting their homes are equally represented at each time point for this age group (wave 1: 24.9\%; wave 10: $26.9 \%$ ). For the age groups 30 years and over, home ownership is the dominant tenure state at each wave, slowly increasing, but not as steeply as for the younger age groups (wave 1: 62.0\%; wave 10: $71.8 \%$ ).

Figure A6 shows transversal housing tenure states by marital status at wave one. Individuals legally married at wave one were dominantly home owners, with $81.2 \%$ owning their homes. This percentage was stable throughout the ten waves. On the contrary, home owners were only represented by $15.5 \%$ of individuals who were never married and not in a de facto relationship at wave one. The dominant housing tenure for this marital status at wave one was living with parents (52.2\%). By wave ten, this trend is reversed; with only $13.0 \%$ of individuals living with their parents and $44.4 \%$ being home owners. Individuals who were in a de facto relationship or separated/divorced/widowed at wave one had a relatively stable proportion of approximately $50 \%$ in home ownership at each wave, and a $30 \%-40 \%$ of individuals renting in the private sector. The group of individuals that were separated, divorced or widowed at wave one were consistently the highest proportion of individuals renting in the public sector (wave 1: 9.9\%; wave 10: 9.6\%).

Housing tenure pathways grouped by the individuals' employment status at wave one showed clear differences in the state distributions for individuals employed, unemployed or not in the labour force at wave one. For individuals employed at wave one, the proportion of home owners increased from $61.4 \%$ at wave one to $74.3 \%$ at wave 10 . A proportion of $23.2 \%$ and $44.8 \%$ of individuals unemployed or not in the labour force at wave one, respectively, were home owners. This percentage increased by roughly $10 \%$ in both groups by wave ten. The group of individuals who were unemployed at wave one show consistently the largest proportion of individuals renting in the private sector (wave 1: $35.0 \%$; wave 10: $41.4 \%$ ) and a consistent proportion of $8 \%$ renting in the public sector (Figure A7).

Figure A8 shows that $31.9 \%$ of individuals with no children at wave one were in home ownership; this proportion increased to $56.6 \%$ at wave ten. The proportion of individuals renting in the private sector stayed stable at around $30 \%$ and the proportion of individuals living with their parents decreased from 
$32.8 \%$ at wave 1 to $8.5 \%$ at wave ten for individuals with no children at wave one. Individuals with children aged five and under and with children aged 6-18 years had a similar and stable tenure state distribution across all ten waves: at wave one $75.2 \%$ and $81.6 \%$ are home owners, $18.8 \%$ and $14.0 \%$ are renters (private), $3.5 \%$ and $2.6 \%$ are renters (social), $2.0 \%$ and $1.3 \%$ are in a another tenure, and $0.5 \%$ living with parents, for individuals with children aged five and under and for individuals with children aged 6-18 years respectively. Individuals with children older than 18 years are only represented by 6 individuals at wave one, however, at wave ten there are 281 individuals who have adult children in the household and the majority are home owners (84\%).
In summary, almost half of the housing tenure sequences (48.1\%) are home owners already and have been for the whole period from 2001 to 2010, or are transitioning sometime throughout this period into home ownership. Examining the transversal state frequencies of tenure status by various demographic characteristics shows distinctive changes in the frequencies of tenure status over time, particularly for individuals who are under the age of 30 at wave one, have never been married and are not in a de facto relationship, are either unemployed or not in the labour force and have no own children in the household.

\section{Figure A5. Transversal state frequencies of tenure status by age group at Wave 1}

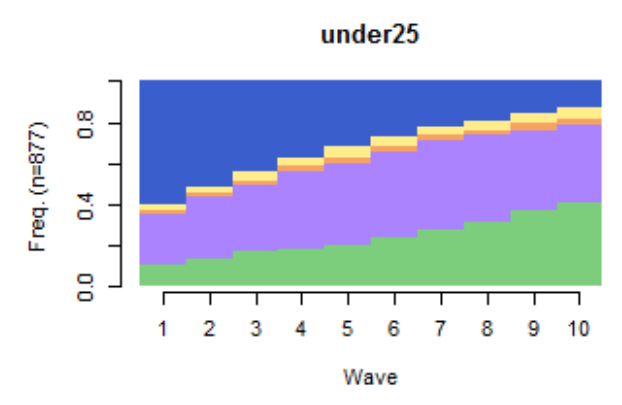

$30-34$
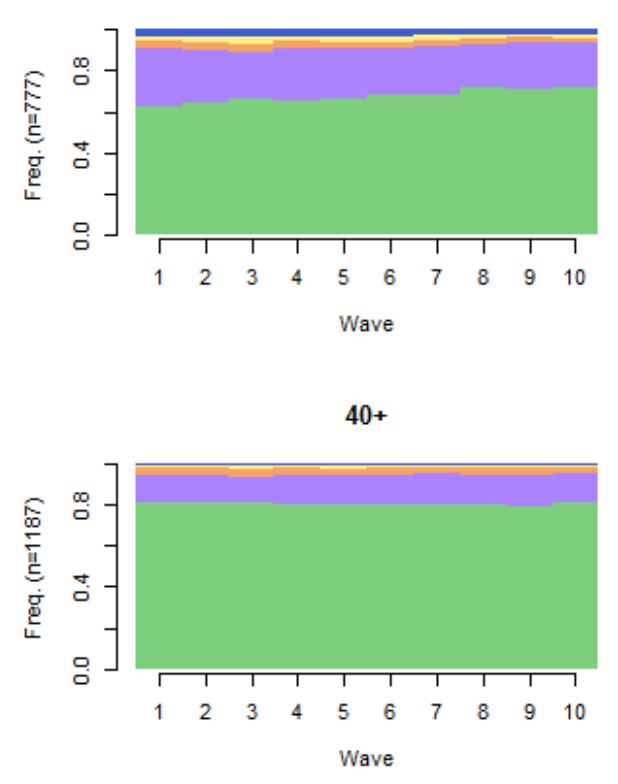

25-29

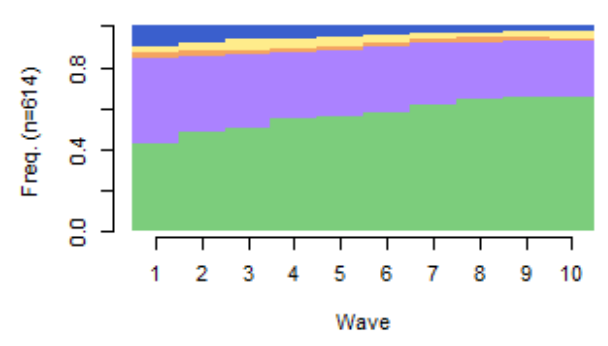

35-39

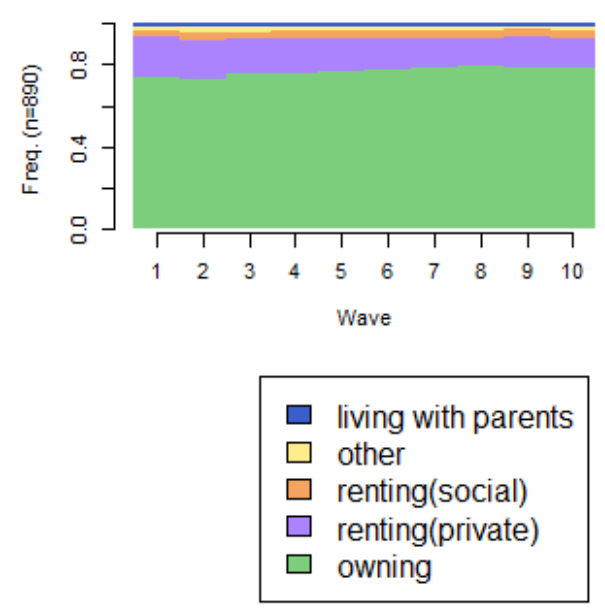


Figure A6. Transversal state frequencies of tenure status by marital status at Wave 1.
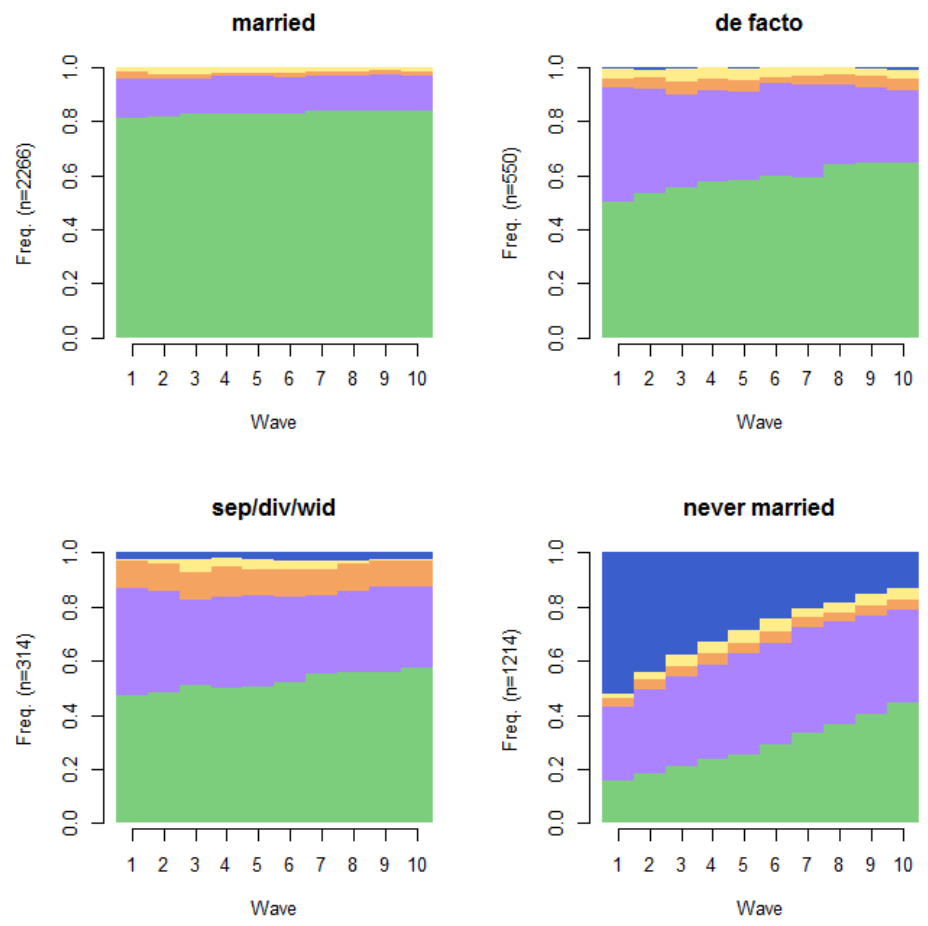

Figure A7. Transversal state frequencies of tenure status by employment status at Wave 1.
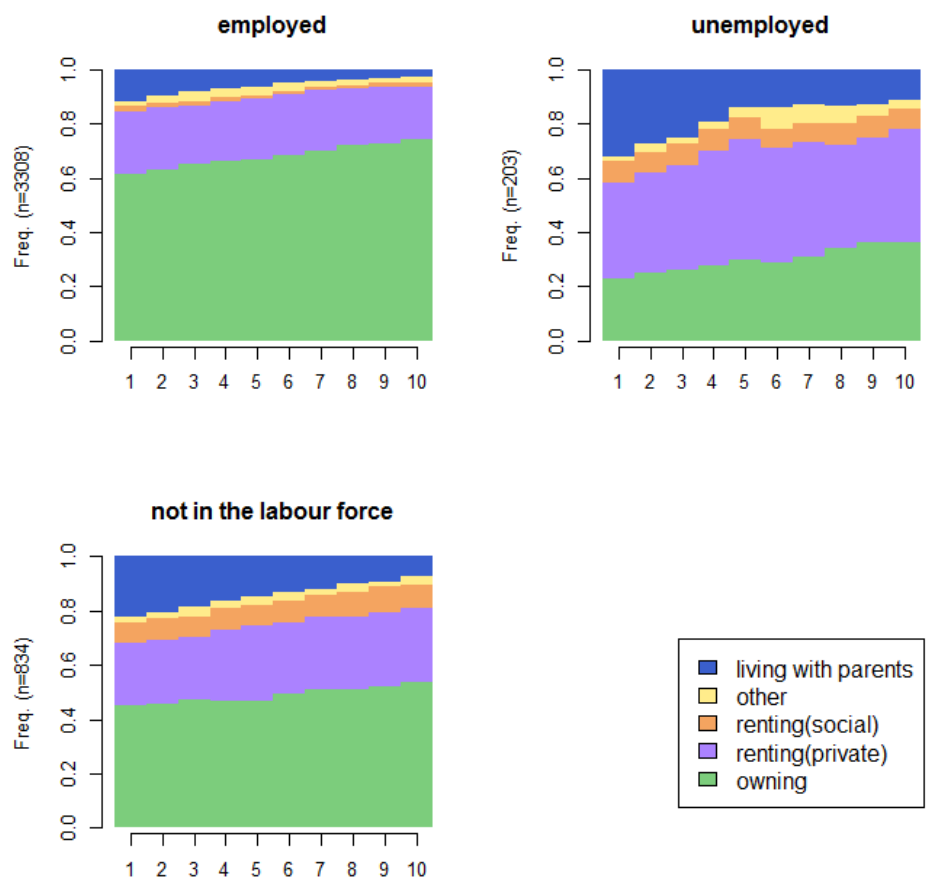

$$
\begin{aligned}
& \square \text { living with parents } \\
& \square \text { other } \\
& \square \text { renting(social) } \\
& \square \text { renting(private) } \\
& \square \text { owning }
\end{aligned}
$$


Figure A8. Transversal state frequencies of tenure status by age of youngest child at Wave 1.
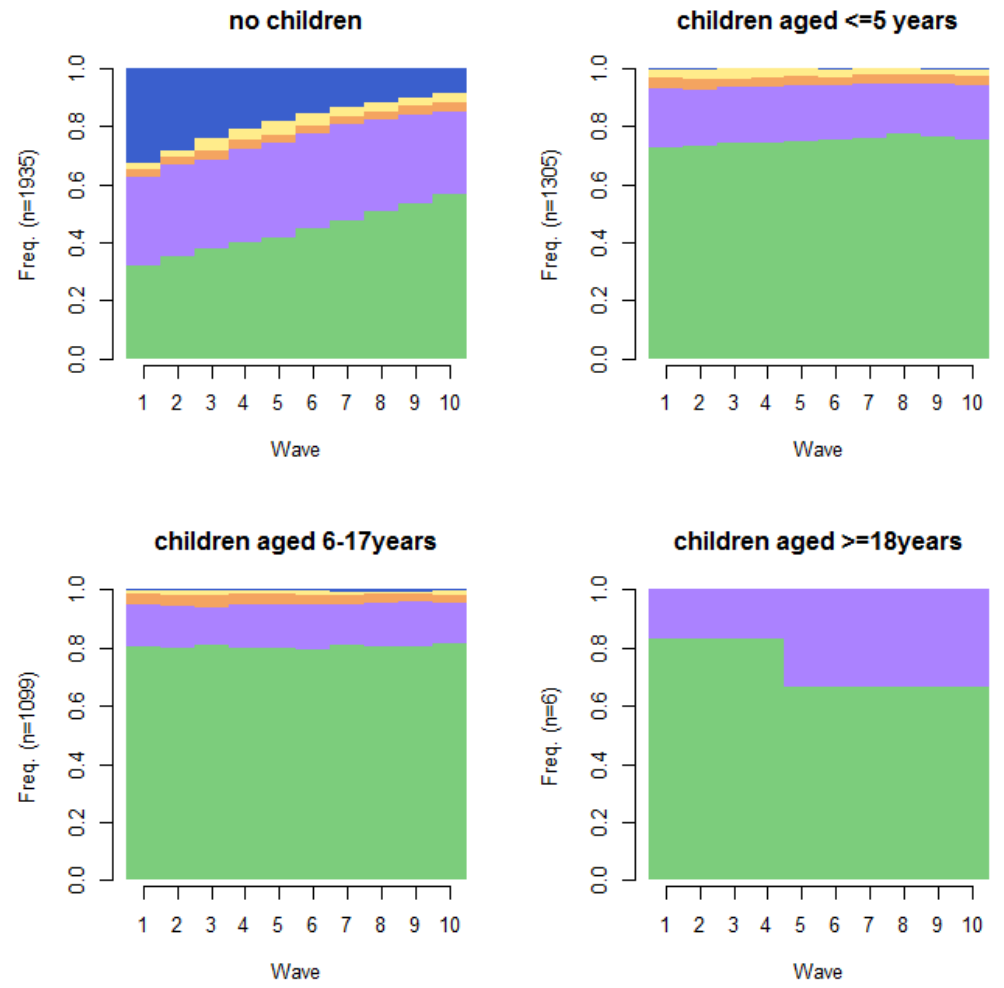

$\square$ living with parents $\square$ renting(private)
$\square$ other
$\square$ renting(social)

\section{References}

Abbott, A., \& Tsay, A. (2000). Sequence analysis and optimal matching methods in sociology - Review and prospect. Sociological Methods \& Research, 29, 3-33. http://dx.doi.org/10.1177/0049124100029001001

Allison, P. (2009). Sequence Analysis and Optimal Matching Gechniques for Social Science Data. In A. H. Bryman, Melissa A. (Ed.), Handbook of Data Analysis. London, UK: Sage Publications Ltd.

Badcock, B., \& Beer, A. (2000). Home Truths. Melbourne: Melbourne University Press.

Baizan, P., Aassve, A., \& Billari, F. C. (2004). The interrelations between cohabitation, marriage and first birth in Germany and Sweden. Population and Environment, 25, 531-561. http://dx.doi.org/10.1023/B:POEN.0000039064.65655.3b

Beer, A., \& Faulkner, D. (2009). 21st century housing careers and Australia's housing future. Melbourne: Australian Housing and Urban Research Institute.

Beer, A., Paris, C., Faulkner, D., \& Clower, T. (2011). Housing Transitions through the life course. Bristol: The Policy Press.

Boyle, P. J., Kulu, H., Cooke, T., Gayle, V., \& Mulder, C. H. (2008). Moving and union dissolution. Demography, 45, 209-222. http://dx.doi.org/10.1353/dem.2008.0000

Clapham, D. (2005). The meaning of housing - A pathwyays approach. Bristol: The Policy Press. http://dx.doi.org/10.1332/policypress/9781861346384.001.0001

Clark, W. A. V., Deurloo, M. C., \& Dieleman, F. M. (2003). Housing Careers in the United States, 1968-93: Modelling the Sequencing of Housing States. Urban Studies, 40, 143-160. http://dx.doi.org/10.1080/00420980220080211

Clark, W. A. V., \& Huang, Y. (2003). The life course and residential mobility in British housing markets. Environment and Planning A, 35, 323-339. http://dx.doi.org/10.1068/a3542 
Elder, G. H., Jr. (1978). Approaches to social change and the family. American Journal of Sociology, 84, S1S38. http://dx.doi.org/10.1086/649235

Elder, G. H., Jr. (1985). Life course dynamics: trajectories and transitions, 1968-1980. Ithaca, NY: Cornell University Press.

Elder, G. H., Jr. (2003). The Emergence and Development of Life Course Theory. In J. T. Mortimer \& M. J. Shanahan (Eds.), Handbook of the Life Course (pp. 3-19). New York: Kluwer Academic/Plenum Publishers. http://dx.doi.org/10.1007/978-0-306-48247-2 1

Feijten, P., \& Mulder, C. H. (2002). The Timing of Household Events and Housing Events in the Netherlands A longitudinal Perspective. Housing Studies, 17, 773-792. http://dx.doi.org/10.1080/0267303022000009808

Gabadinho, A., Ritschard, G., Muller, N. S., \& Studer, M. (2011). Analyzing and Visualizing State Sequences in $\mathrm{R}$ with TraMineR. Journal of Statistical Software, 40, 1-37.

Gauthier, J.-A., Widmer, E. D., Bucher, P., \& Notredame, C. (2010). Multichannel sequence analysis applied to Social Science data. Sociological Methodology, 40, 1-38. http://dx.doi.org/10.1111/i.14679531.2010.01227.x

George, L. K. (1993). Sociological Perspectives on Life Transition. Annual Review of Sociology, 19, $353-373$. http://dx.doi.org/10.1146/annurev.so.19.080193.002033

Giddens, A. (1991). Modernity and self identity: Self and society in the late modern age. Cambridge: Polity Press.

Ginsburg, C., Steele, F., Richter, L. M., \& Norris, S. A. (2010). Modelling Residential Mobility: Factors Associated with the Movement of Children in Greater Johannesburg, South Africa. Population, Space and Place, 17, 611-626.

Harley, C., \& Mortimer, J. T. (2000). Social status and mental health in young adulthood: The mediating role of the transition to adulthood. Paper presented at the Biennial Meeting of the Society for Research on Adolescence, Chicago, March 30-April 2.

Hogan, D. P., \& Astone, N. M. (1986). The Transition to Adulthood. Annual Review of Sociology, 12, $109-130$. http://dx.doi.org/10.1146/annurev.so.12.080186.000545

Hunt, S. (2005). The Life Course: A Sociological Introduction. Gordonsville: Palgrave Macmillan.

Kaufmann, L., \& Rousseeuw, P. J. (2005). Finding Groups in Data. Hoboken: John Wiley \& Sons.

Kendig, F. (1982). Will a Home Still Be a House. Institutional Investor, 16, 89-91.

Kendig, H. (1981). Buying and Renting: Household Moves in Adelaide. Canberra: Australian Institute of Urban Studies, Canberra.

Kendig, H. L. (1984). Housing Careers, Life-Cycle and Residential-Mobility - Implications for the HousingMarket. Urban Studies, 21, 271-283. http://dx.doi.org/10.1080/00420988420080541

Kulu, H. (2005). Migration and fertility: Competing hypotheses re-examined. European Journal of PopulationRevue Europeenne De Demographie, 21, 51-87. http://dx.doi.org/10.1007/s10680-005-3581-8

Kulu, H. (2008). Fertility and spatial mobility in the life course: evidence from Austria. Environment and Planning A, 40, 632-652. http://dx.doi.org/10.1068/a3914

Kulu, H., \& Milewski, N. (2007). Family change and migration in the life course: An introduction. Demographic Research, 17, 567-590. http://dx.doi.org/10.4054/DemRes.2007.17.19

Martin, P., \& Wiggins, R. D. (2011). Optimal Matching Analysis. In M. Williams \& P. W. Vogt (Eds.), The SAGE Handbook of Innovation in Social Research Methods (pp. 385-408). London: SAGE Publications Ltd. http://dx.doi.org/10.4135/9781446268261.n22

McDonald, P., \& Merlo, R. (2002). Housing and its association with other life outcomes. Melbourne: Australian Housing and Urban Research Institute.

McLeod, P. B., \& Ellis, J. R. (1982). Housing Consumption Over the Family Life Cycle: an Empirical Analysis. Urban Studies, 19, 177-185. http://dx.doi.org/10.1080/00420988220080301

Michielin, F., \& Mulder, C. H. (2008). Family events and the residential mobility of couples. Environment and Planning A., 40, 2770-2790. http://dx.doi.org/10.1068/a39374

Mulder, C. H. (2006). Home-ownership and family formation. Journal of Housing and the Built Environment, 21, 281-298. http://dx.doi.org/10.1007/s10901-006-9050-9

Mulder, C. H., \& Lauster, N. T. (2010). Housing and Family: An Introduction. Housing Studies, 25, $433-440$. http://dx.doi.org/10.1080/02673031003771109

Neugarten, B. L., \& Datan, N. (1973). Sociological perspecitves on the life cycle. In P.B. Baltes \& K.W. Scheie (Eds.), Life-span developmental psychology: Personality and socialization, (pp. 53-69). New York: Academic Press. http://dx.doi.org/10.1016/B978-0-12-077150-9.50009-5

Payne, J., \& Payne, G. (1977). Housing pathways and stratification: a sudy of life changes in the housing market. Journal of Social Policy, 23, 125-156.

Pollock, G. (2007). Holistic trajectories: a study of combined employment, housing and family careers by using multiple-sequence analysis. Journal of the Royal Statistical Society Series a-Statistics in Society, 170, 167-183. http://dx.doi.org/10.1111/j.1467-985X.2006.00450.x

R Core Team (2013). R: A Language and Environment for Statistical Computing. R Foundation for Statistical Computing, Vienna, Austria. 
Rossi, P. H. (1955). Why families move. Glencoe, Illiinois: The Free Press.

Stovel, K., \& Boland, M. (2004). Residential Trajectories: Using Optimal Alignment to Reveal the Structure of Residential Mobility. Sociological Methods \& Research, 32, 559-598. http://dx.doi.org/10.1177/0049124103262683

Studer, M., Ritschard, G., Gabadinho, A., \& Mueller, N. S. (2011). Discrepancy Analysis of State Sequences. Sociological Methods and Research, 40, 471-510. http://dx.doi.org/10.1177/0049124111415372

Winter, I., \& Stone, W. (1999). Home Ownership: Off Course? In J. Yates \& M. Wulff (Eds.), Australia's Housing Choices (pp. 43-52). Brisbane: The University of Queensland Press.

Wooden, M., \& Watson, N. (2001). The Household, Income and Labour Dynamics in Australia (HILDA) Survey: An Introduction to the Proposed Survey Design and Plan. Melbourne: The University of Melbourne, Department of Family and Community Services.

Yates, J. (2007). Has the great Australian dream ended? Paper presented at the Centre for Public Policy Conference 21-22 February, Jasper Hotel, 489 Elizabeth Street, Melbourne.

Yates, J. (2008). Australia's housing affordability crisis. The Australian Economic Review, 41, $200-214$. http://dx.doi.org/10.1111/j.1467-8462.2008.00502.x

Yates, J., \& Bradbury, B. (2010). Home ownership as a (crumbling) fourth pillar of social insurance in Australia. Journal of Housing and the Built Environment, 25, 193-211. http://dx.doi.org/10.1007/s10901-010-9187-4 